\title{
The Sustainable Development of Railway System in Vietnam by GIS-based Technologies
}

\author{
Khanh Giang Le ${ }^{1 *}$, Quang Hoc Tran ${ }^{1}$, \\ ${ }^{1}$ Faculty of Civil Engineering, University of Transport and Communications, Hanoi, Vietnam
}

\begin{abstract}
This study aims to explore the applications of Geographical Information System (GIS) technology in managing and analysing the railway networks in Vietnam in a scientific and rational manner, developing the railway industry in a sustainable manner to keep pace with the development speed in the region and in the world. A process of building a GIS project and designing a geodatabase for a GIS project was proposed. From that point, it is suggested to build an experimental database for the railway networks of Vietnam through ArcGIS software 10.2. After that, the authors explored some typical applications of GIS technology for railway network management such as management, safety and security, and selecting optimum routes. The results showed that GIS application in managing railway system brings lots of benefit to not only in the railway sector but also in the transportation field.
\end{abstract}

\section{Introduction}

Railway networks play an important role in a transportation system in a country. More importantly, railroad transportation system always plays a significant part in logistics infrastructure system in a nation. Over the world, in developed countries, railway networks have been invested and developed adequately in its role. In these countries, railway transportation is preferred than other types of traffic because of the great benefits that it offers such as friendly, safety, cheap, and fast, etc. Their railway networks and related support infrastructure systems have been significantly invested. The critical movement of goods as well as services was supported by these systems. The smooth operation of the railway plays a very important role. Any incident happens on the railway system can result in serious congestion, delays, and safety issues [1]. Meanwhile, in Vietnam, railway transportation is always the last option even for low-income people. Vietnam's railway system is too backward compared to other countries in the world such as Japan [2]. It has not been invested adequately in its role and has not applied advanced technologies in planning, designing, constructing, managing, and operating [3].

In order to develop the railway system in a sustainable way, in addition to new investment, the current railway networks need to be upgraded with the application of information

* Corresponding author: gianglk@utc.edu.vn 
technology and modernization of infrastructure. Research on applications of Geographical Information System (GIS) into the railway sector is a great opportunity. In the last decades, GIS has been developing as a powerful technology in managing and planning urban resources. GIS enables us to collect, store, manipulate, query, analyze, and visualize the huge amounts of spatial data, leading to the popularly applications of GIS in many sectors [4-9]. Automated mapping, data capture, and surveying analysis tools enable us to create maps effectively, exactly, and visually. What is occurring within a set distance of a feature will be found out easily. GIS enables us to discover the relationships among the railway system and the natural as well as human environment. GIS provides great chances in managing railway networks. The integrating performance of spatial analysis, 3D, and network analysis using diverse spatial layers such as hydrology, surface, slope, land cover and heritage database enable us to understand situations comprehensively [10].

The past studies showed that the GIS applications in managing cultural heritage were studied by many authors, see e.g., $[10,11]$. The relationship between urbanization and railway was explained by [12]. However, GIS applications in safety and security railway management are limited. In Vietnam, although GIS has been known for a long time, its applications to the railway sector are still new. Therefore, in this paper, the authors will explore and point out several benefits that GIS can bring to the sustainable development of the railway system in particular and the transportation system in general in Vietnam. The study proposed a methodology in building a database for a GIS project, and then several applications of GIS in railway sectors were analyzed in a case study of Vietnam.

\section{Study area}

The principal route, the single track North-South Railway running between Hanoi and Ho Chi Minh City, accounts for 1,726 km of the network's total length of 3,143 km. There were 278 stations on the Vietnamese railway network, 191 of which were located along the NorthSouth line.

\section{Methodology and results}

\subsection{The process of building a GIS project}

The steps of building a GIS project are shown in Fig. 1. Initially, the project objectives need to be determined clearly. This is a very important step in a GIS project because it helps to identify which data need to be collected. After collecting data, we carried out the preparation of data such as clearing, converting, or integrating. GIS enables us to store many types of data. By using ArcCatalog of ArcGIS, it enables us to store data systematically and easily. In the next step, we can implement many kinds of queries and analyses. Finally, the outcomes are displayed on the maps, figures, or reports.

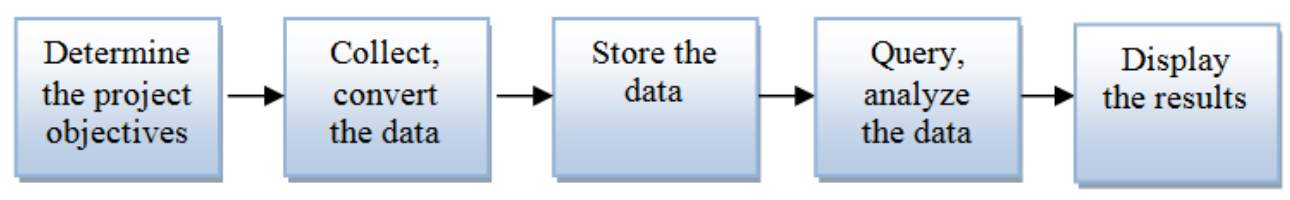

Fig. 1. Diagram of steps to build a GIS project. 


\subsection{The process of building a geodatabase for a GIS project}

The steps of building a geodatabase for a GIS project are shown in Fig. 2. A geodatabase is a standard relational database diagram generated in the ArcGIS platform by ESRI. It effectively defines and illustrates spatial entities, systematizes their constraint relationship, and makes the defined model close as its state in the real world. A geodatabase enables unified management of geographic data in many types of formats, enabling multiple users to access and modify the same geographic area simultaneously [10].

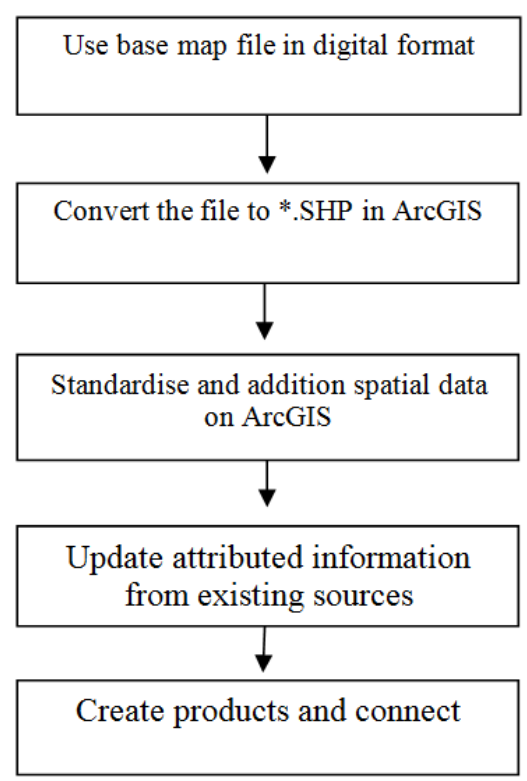

Fig. 2. Diagram of building the GIS database on ArcGIS.

\subsubsection{Building of a practical geodatabase}

A geodatabase for railway networks was built which focuses on the Northern areas of Vietnam. From the collected data, the geodatabase was designed in ArcCatalog, and then the geodatabase was illustrated in ArcMap, as shown in Fig. 3. 


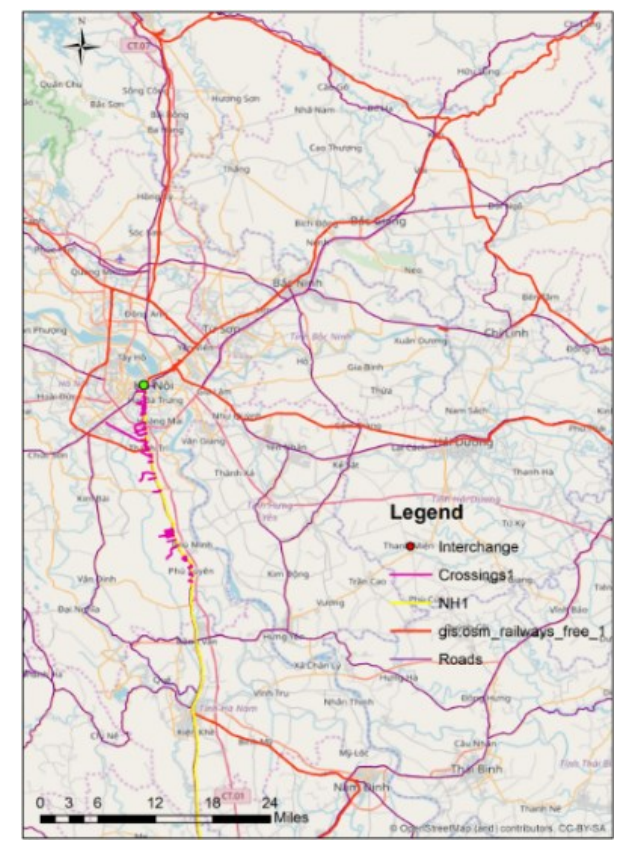

Fig. 3. Classified objects on ArcMap.

\subsubsection{Data entry process}

Spatial data import: From the geographic background data collected from the Map Data Storage Center, the spatial data entry for the objects is formatted as points, lines, areas and is executed by ArcCatalog.

Attribute data entry: Attribute data are stored as tables, which are collected from the annual statistics. Attribute data is built directly on ArcMap. The next step is to name the field and set the data type for each field as either integer, double, or text which are the three data types used, see Table 1 .

Table 1. The attribute data for the rail object after being entered into ArcGIS.

\begin{tabular}{|c|c|c|c|c|c|c|c|}
\hline Tat & & & & & & $\square>$ & $x$ \\
\hline & 厚 & 觢・喕 & $\square \times$ & & & & \\
\hline & chan & & & & & & $x$ \\
\hline & FID & Shape & OBJECTID & $\mathrm{Ma}$ & Railroad_name & Distance & a \\
\hline & 0 & Polyline & 2 & HBO & Hà Nội - Hồ Chi Minh & 174006.1599 & \\
\hline & 1 & Polyline & 3 & HBO & Hà Nội - Hồ Chi Minh & 185809.1348 & \\
\hline & 2 & Polyline & 4 & HBO & Hà Nội - Hồ Chi Minh & 4987.6329 & \\
\hline & 3 & Polyine & 5 & HBO & Hà Nội - Hồ Chí Minh & 1235.1782 & \\
\hline & 4 & Polyline & 6 & HBO & Hà Nội - Hồ Chí Minh & 45412.7028 & \\
\hline & 5 & Polyline & 7 & HBO & Hà Nội - Hồ Chi Minh & 217256.818 & \\
\hline & 6 & Polyline & 8 & HBO & Diêu Tri - Quy Nhơn & 9520.4909 & \\
\hline & 7 & Polyline & 9 & HBO & Hà Nội - Hồ Chi Minh & 297781.7162 & \\
\hline & 8 & Polyine & 10 & HBO & Hà Nội - Đà Nắng & 3890.4266 & \\
\hline & 9 & Polyline & 11 & HBO & Hà Nội - Hồ Chi Minh & 290343.7066 & \\
\hline & 10 & Polyline & 12 & HBO & Hà Nội - Hồ Chí Minh & 171463.5799 & \\
\hline & 11 & Polyline & 13 & HBO & Hà Nội - Giáp Bát & 15906.8353 & \\
\hline & 12 & Polyine & 14 & HBO & Hà Nội - Hài Phòng & 100561.0504 & \\
\hline & 13 & Polyine & 15 & HBO & Hà Nội - Lạng Sơn & 5209.9547 & \\
\hline & 14 & Polyine & 16 & HBO & Hà Nội - Lào Cai & 10309.1418 & \\
\hline & 15 & Polyline & 17 & HBO & Giáp Bát - Đông Anh & 38209.2691 & \\
\hline & 16 & Polyline & 18 & HBO & Hà Nội - Lào Cai & 5751.878 & \\
\hline & 17 & Polyline & 19 & HBO & Hà Nội - Lạng Sơn & 56120.2935 & \\
\hline & 18 & Polyline & 20 & HBO & Hà Nội - Quàng Ninh & 103471.7096 & \\
\hline & 19 & Polyline & 21 & HBO & Hà Nội - Lạng Sơn & 3398.6418 & \\
\hline & 20 & Polyine & 22 & HBO & Bắc Giang - Thái Nguyên & 57047.5837 & - \\
\hline & & & & III & & 1 & \\
\hline 1 & 1 & & " 厚 & $(0$ & out of 33 Selected) & & \\
\hline
\end{tabular}




\subsection{Application of GIS in managing railway networks}

\subsubsection{Management}

With the ability to overlay the GIS data layers, this makes infrastructure database management tasks easy, intuitive, and aggregated. If the entire database should be shown, all layers have to be turned on, as shown in Fig. 4. In contrast, if a layer of data should be displayed, only the data layer has to be turned on, as shown in Fig. 5.

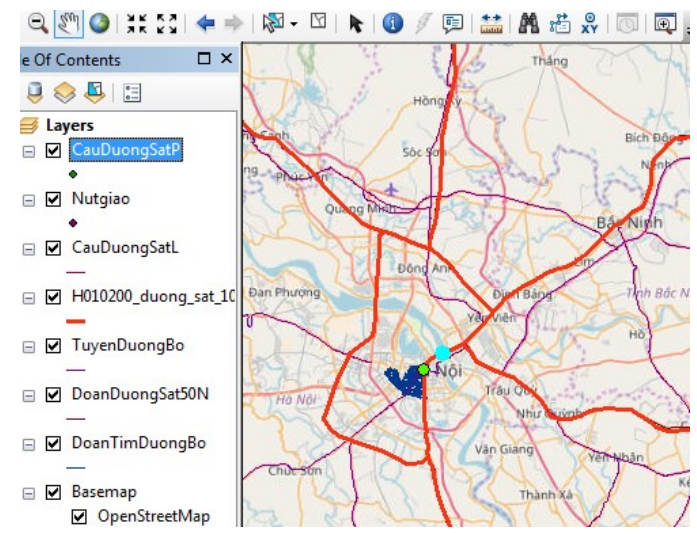

Fig. 4. Integrated map of the infrastructure data layers of North of Vietnam.

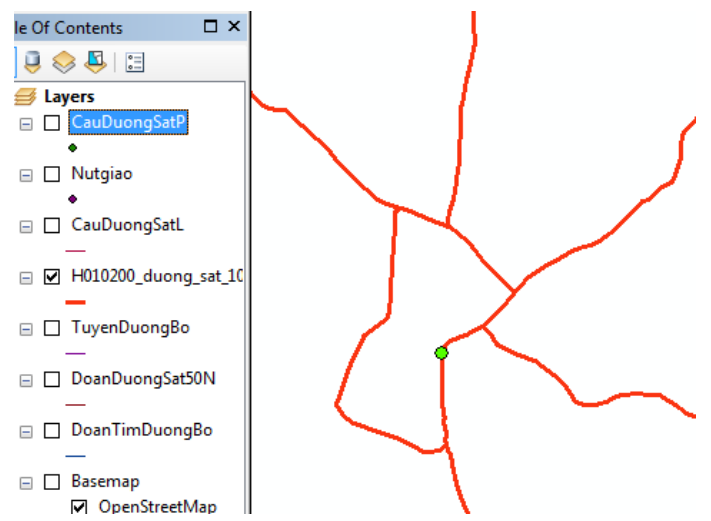

Fig. 5. Map of a railway data layer.

Currently, there are 1,452 bridges on the railway system in Vietnam, but nearly half of them are degraded and no investment has been made. The load of road and bridge on the railway system is not synchronous; leading to reduced transport ability of the entire route. It is necessary to determine the bridges that need to be repaired or rebuild.

With the ability of GIS query, this makes the railway database management model by GIS technology easy to implement as shown in Fig. 6. For example, to find the bridge named Phu Binh located on the railway system and its attributes, the query can be done by the blue color point on the map, which is Phu Binh Bridge, as shown in Fig. 7. 


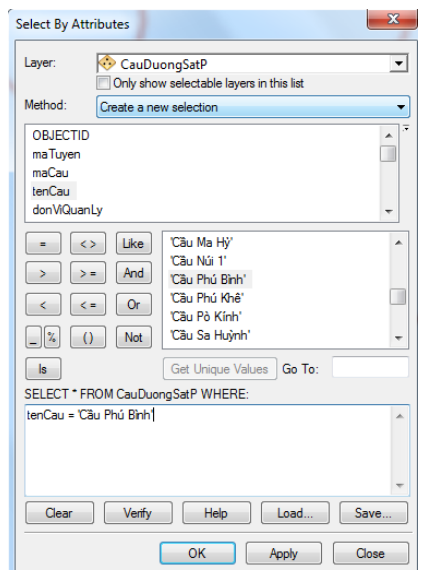

Fig. 6. Query methods

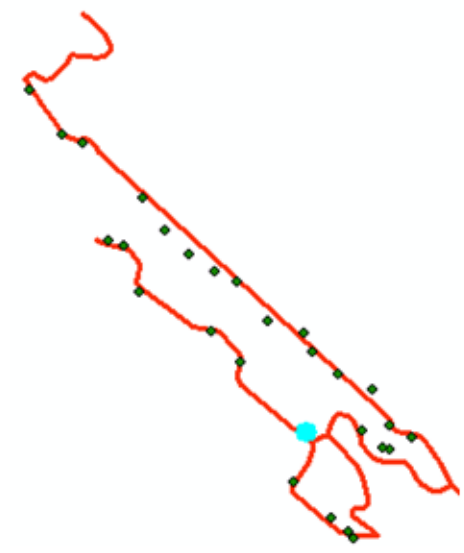

Fig. 7. The result on the map

\subsubsection{Safety and security}

Statistics show that for every $1 \mathrm{~km}$ of railway there are 1.85 crossroads. The railway safety corridor of many sections was seriously violated. This is considered to be a cause of speed limit and railroad accidents. In recent years, railway safety and security issues have been considered significantly, especially in densely populated urban zones. Well-developed GIS systems enable to determine in detail non-railroad assets in the communities, which were developed by railroad managers. Railway authorities use GIS for access to local data such as streets, at-grade crossings, police, fire, rescue contact information, schools, hospitals, rivers, and other geographic features needed to better manage incidents and emergencies in cases of crime, crashes, spills, or other unusual events.

Vietnam Rail (VNR) Company currently manages $3,143 \mathrm{~km}$ of railways, including $2,632 \mathrm{~km}$ of main railways, $403 \mathrm{~km}$ of railway lines at stations, $108 \mathrm{~km}$ of branch railways; passing through 34 provinces and cities. Most railroads run parallel to national roads and through densely populated urban and industrial areas, which in turn leads to the illegal opening of intersections between railways and roads, as shown in Fig. 8 and 9.

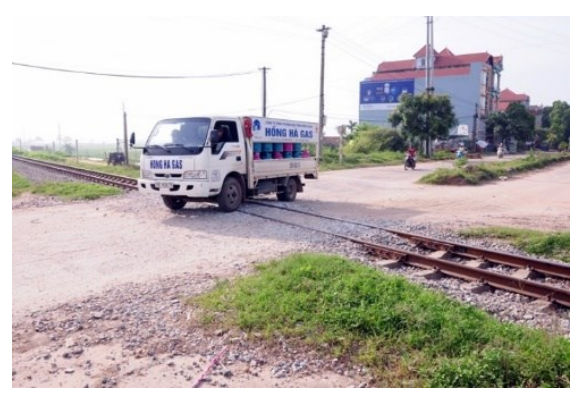

Fig. 8. The intersection has no barrier [13]

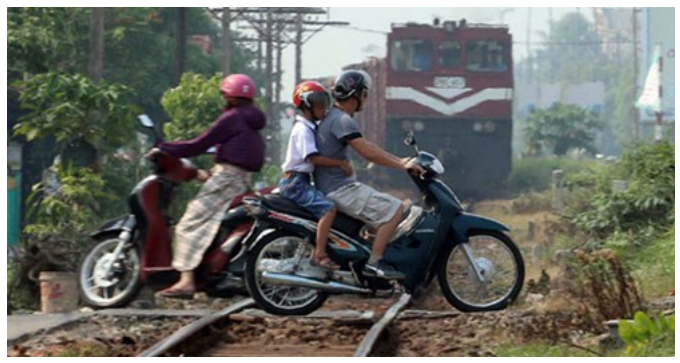

Fig. 9. The intersection has no barrier [14]

Statistics show that there are more than 5,700 intersections across the national rail network, including 1,516 legal crossings and 4,268 illegal passages. These are potentially high risk points for railway traffic. To implement the regulations on coordination in ensuring traffic order at the crossings between railways and roads, the railways and localities have made great efforts in closing the illegal crossings. However, the issue of railway traffic safety is still very 
complicated.

With so many complicated intersections, management based only on the reports without associating it with geographic location with visual imagery is difficult for the managers. GIS technology will help solve this problem. Using the existing road and rail traffic data sets and the GIS overlay tool, the intersection points can be identified. Through field surveys, points without warning barriers or frequent accidents are classified as black spots that need to be repaired and priorities are also expressed in colors in ArcGIS as shown in Fig. 10 and 11.

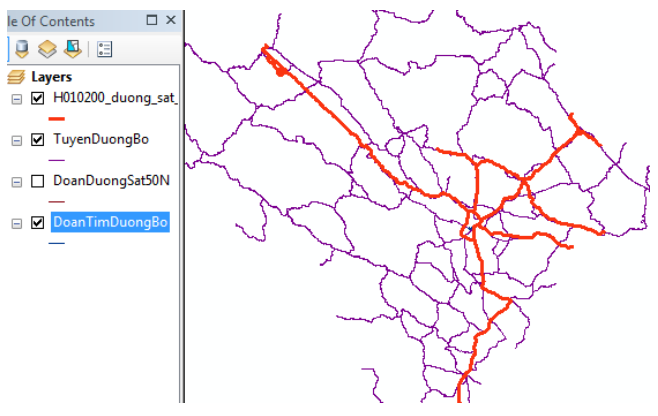

Fig. 10. Overlay map of roads and railways

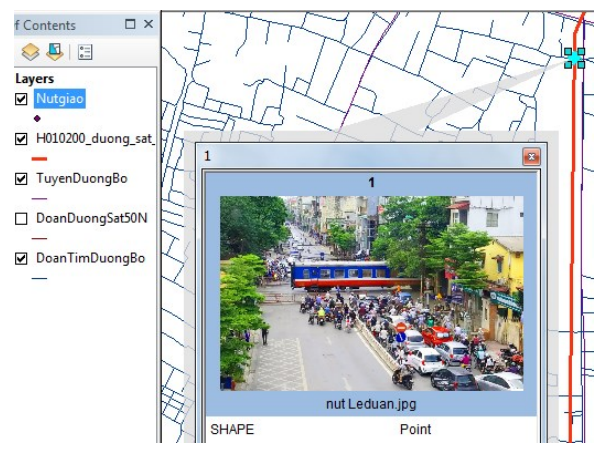

Fig. 11. The intersection with image

Visual maps combined with the accompanying properties and illustrations will help managers quickly resolve black spots practically, accurately, and efficiently.

To minimize the black spots, VNR Corporation has proposed that prioritize the construction of access roads and fences to eliminate illegal passages. Besides, the construction of new projects, renovation, and upgrading of national highways, provincial roads intersected with railways must organize crossovers. In special cases where crossings are to be made, the system of collecting roads must be made to gather the place where the intersections are legally available. Based on overlaying tool of GIS, planners will have a reasonable plan to build the collection roads. In addition, it is necessary to integrate aerial and satellite images with facility maps, which brings location information in detail and context both for analysts and field personnel.

Besides, external information such as real-time weather data can also be applied in railway GIS to adapt speed or other rail traffic activities. This weather data type can also be critical information to support in case of evacuations. Flood levels can also be integrated and alternate routing organized safely and efficiently, minimizing reversed or uncompleted trips. Similarly, it is possible to integrate information about dangerous, easily erosion sections.

GIS enables rail managers to manage shipments and transfers more effectively by giving them more accurate and timely information, an essential feature in any decision support system. GIS also supports the development of "executive dashboards," bringing the benefits of spatial information and intuitive map graphics directly to facility and operations managers.

\subsubsection{Selecting optimum routes}

Analytic Hierarchy Process (AHP) is one of the most famous methods widely applied to solve Multi Criteria Decision Making (MCDM) problems. The necessary datasets were reclassified as a final step, then the layers were weighted using AHP [15].

The model of a reasonable site was built by using a model builder in ArcGIS 10.2. It was built by the multi-criteria evaluation methodology in which the weight of the relative 
significance found to every criterion and an aggregate score is then led for every paradigm by multiplying the relative significance percentage by the scale an incentive for that criterion (Fig. 12).

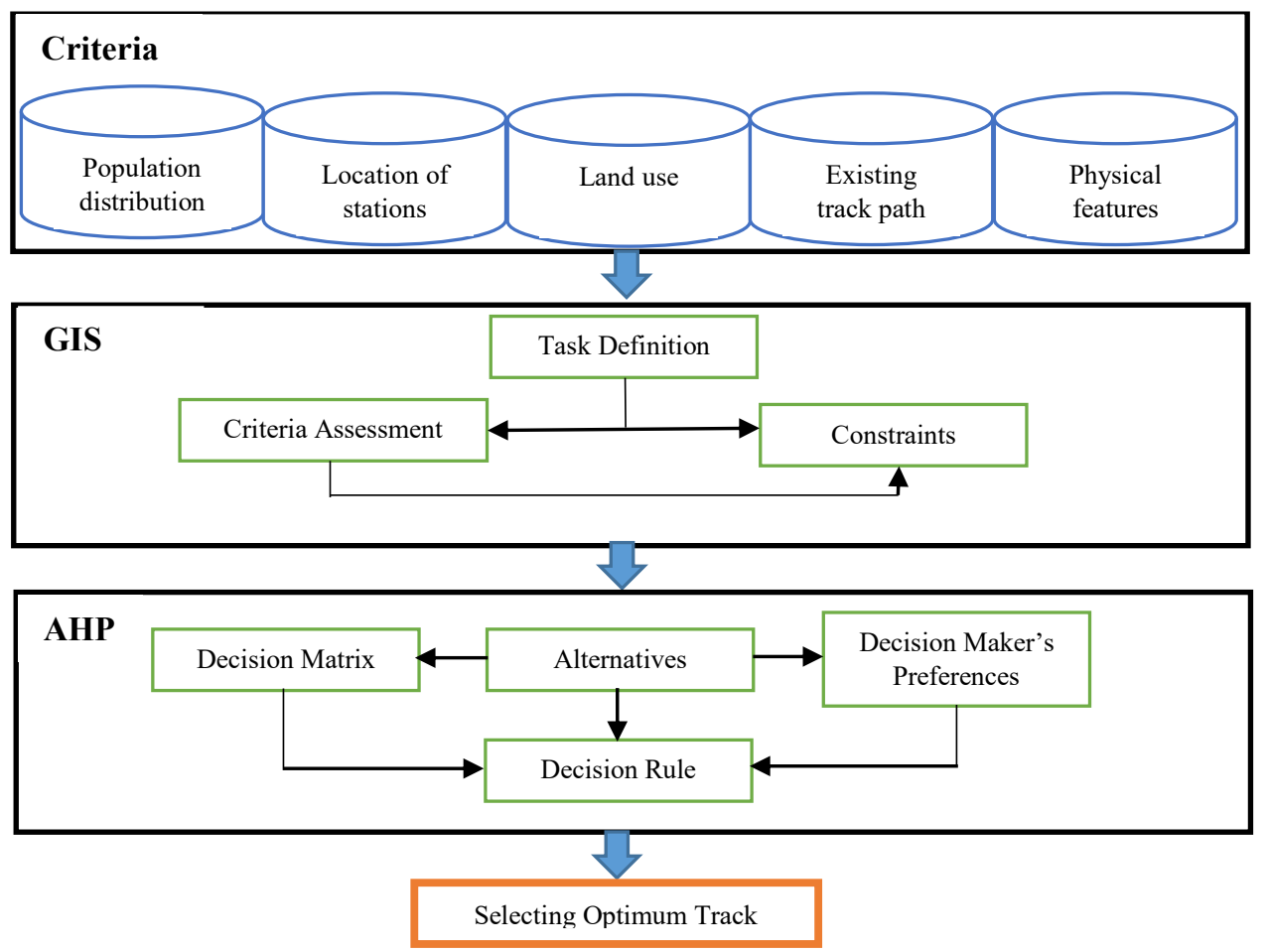

Fig. 12. Diagram of selecting optimum routes

\section{Conclusions and recommendations}

A comprehensive GIS for railway in Vietnam has been presented. It shows that such system is successful in several issues including determination of the railway accident black spots, vulnerable positions, intersections with the roadways, or the best path to get the accident location and perform emergency services.

The railway infrastructure database is very large and therefore requires an appropriate management system. In this paper, the authors present a way to manage the railway network database scientifically with ArcGIS software.

GIS technology allows the linking of spatial objects with their attribute data, thus allowing managers to easily organize the transport infrastructure database accurately and reliably. It helps managers to get their desired results through simple but accurate query steps. With more and more databases, updating data is not a problem, managers simply need to open updated attribute data or they can synthesize data in tabular and unstructured formats and associate with the attribute data of the objects.

In this article, the authors build a database on ArcGIS software, but when deploying, it is necessary to build a software system to facilitate the management, statistics and updating of data whether convenient and appropriate to the qualifications and conditions of the direct manager. 


\section{References}

1. D. Schut, J. Wisniewski, a Global Vision for Railway Development, International Railway Research Board, (2015).

2. F. Kurosaki, Reform of the Japanese national railways (JNR), Network Industries Newsletter, 18(4): 8-11, (2016).

3. Q. Toan, Find an opportunity for the Vietnam railroad industry, (2019, October), available: http://special.vietnamplus.vn/duong-sat-viet-nam

4. Goodchild, F. Michael, Twenty years of progress: GIS Science in 2010, Journal of spatial information science, 3-20 (2010).

5. K. T. Chang, Introduction to Geographical Information Systems, New York: McGraw Hill, 184 (2008).

6. J. P. Wilson, A. S. Fotheringham, The Handbook of Geographic Information Science, Malden, MA: Blackwell Publishing, 3-12 (2007).

7. K. G. Le, P. Liu, L. T. Lin, Road Traffic Accident Black Spot Determination by using Kernel Density Estimation Algorithm and Cluster Statistical Significant Evaluation, Paper presented at FIG Working Week 2019, International Conference on Geospatial Information for a Smarter Life and Environmental Resilience, Hanoi City, Vietnam, (2019).

8. K. G. Le, P. Liu, L. T. Lin, Determining the road traffic accident hotspots using GISbased temporal-spatial statistical analytic techniques in Hanoi, Vietnam, Geo-spatial Information Science. 23 (2), 153-164 (2020).

9. K. G. Le, P. Liu, L. T. Lin, Traffic accident hotspot identification by integrating kernel density estimation and spatial autocorrelation analysis: a case study. International Journal of Crashworthiness, 1-11 (2020).

10. K. Sang, S. E. Piovan, The application of GIS in railway heritage management: the case of Yunnan-Vietnam Railway, 29th International Cartographic Conference (ICC 2019), 15-20 July 2019, Tokyo, Japan (2019).

11. F. Petrescu, The use of GIS technology in cultural heritage. In Proceedings of the XXI International CIPA Symposium, Athens, Greece, 2007, pp. 01-06 (2007).

12. J. Atack, F. Bateman, M. Haines, R. A. Margo, Did Railroads Induce or Follow Economic Growth? Urbanization and Population Growth in the American Midwest, 1850-1860, Social Science History, 34(2), 171-197 (2010).

13. N. Lan, 2017, Strengthening solutions to ensure railway safety and order, (2019, October), available: http://baovinhphuc.com.vn/an-ninh-quoc-phong/42022/tangcuong-cac-giai-phap-dam-bao-trat-tu-an-toan-giao-thong-duong-sat.html

14. H. Anh, Delete crossroads: Lack of determination and determination, 2019, available: https://hanoimoi.com.vn/tin-tuc/giao-thong/895751/xoa-duong-ngang-duong-sat-thieukinh-phi-yeu-quyet-tam

15. A. Al-Hameedawi, M. Salih, H. Mohammed, M. Hassan, Selecting optimum railway track using GIS techniques. MATEC Web of Conferences, 162, 03018 (2018). 